\title{
Botulinum toxins in clinical practice
}

\section{Gaps in knowledge}

Richard L. Barbano, MD, PhD

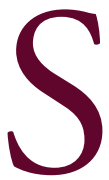

ince the first clinical use of botulinum toxins over a quarter of a century ago, they have proven themselves a versatile tool, especially in the fields of movement disorders and rehabilitation medicine. A practice guideline update on botulinum neurotoxin for the treatment of blepharospasm, cervical dystonia, adult spasticity, and headache has recently been published in Neurology ${ }^{\circledR}{ }^{1}$

For practitioners who have already integrated botulinum toxin injections into their practice, the update offers few surprises. Certainly, important issues regarding payment policies exist. In this issue of Neurology ${ }^{\mathrm{B}}$ Clinical Practice, Govindarajan et al. ${ }^{2}$ discuss some of these issues. From a clinical perspective, the thoroughness of the guideline review provides supporting evidence that botulinum toxin therapy should be considered as a treatment option for cervical dystonia, blepharospasm, adult spasticity, and chronic migraine. Likewise, sufficient data suggest that it should not be offered for episodic migraine. Often times, however, gaps exist in available evidence and in such situations clinical judgment must be exercised. These gaps include the choice of specific botulinum toxin, the use of botulinum toxin in other conditions, and the decision where this therapy fits among various treatment options.

In this updated guideline, the botulinum toxins are addressed as unique products, noting pharmacologic differences between the various preparations such as potency and duration of action, for which evidence exists in animal models. ${ }^{3}$ Each product has its own unique properties including molecular weight and complexing proteins, which can lead to varying clinical properties and side effect profiles. ${ }^{4}$ While the approach of addressing each preparation for different indications is laudable, it does result in questions regarding the interchangeability of the different formulations as well as the use in other indications not covered by the guideline. Lack of evidence of certain preparations in particular indications reminds one of the old adage that "absence of evidence is not evidence of absence."

In regards to the interchangeability of the different products, questions remain as to how different are the products in clinical practice. Certainly, any clinician considering using botulinum toxin in his or her practice must become familiar with the differences between the preparations. Notably, however, head-to-head comparisons, where available, show little clinical differences among the formulations of the botulinum toxin products, especially the different preparations of serotype A. As noted in the guideline, onabotulinum toxin and incobotulinum toxin had the same effect and duration in blepharospasm; onabotulinum toxin, abobotulinum toxin, and rimabotulinum toxin had the same magnitude and duration of effect in cervical dystonia, though rimabotulinum toxin showed increased dysphagia. Thus, in practice, once a provider becomes familiar with appropriate dosing, it is likely that any of these formulations can be used to effectively treat patients with these conditions.

Movement Disorders Division, University of Rochester Medical Center, NY.

Funding information and disclosures are provided at the end of the article. Full disclosure form information provided by the author is available with the full text of this article at Neurology.org/cp.

Correspondence to: richard_barbano@urmc.rochester.edu 
But what about other conditions discussed in the guideline? Not all of the formulations have been shown to be effective in all of the conditions discussed, nor do all formulations have Food and Drug Administration approval for each specific indication. However, off-label use is common in clinical practice. Little data exist to indicate that any of the different formulations, with attention to appropriate dosing and side effects, would not be effective in treating these other conditions. There are also a number of other neurologic conditions not discussed in the guideline in which botulinum toxin has shown efficacy, such as hemifacial spasm and other focal dystonias. ${ }^{5,6}$ Lack of sufficient high-level evidence to support a Level A or B guideline recommendation does not negate their potential utility and likewise, there is little evidence to recommend one formulation over another.

Perhaps one of the more important issues facing practicing neurologists is when to choose to use botulinum toxin therapy. The upcoming years promise to bring major changes to health care delivery. The concept of value has gained increasing importance. This is particularly germane to more costly interventions, and especially true for relatively common conditions, such as chronic migraine and spasticity. For example, while the guideline clearly shows clinically significant improvements in spasticity, for those practitioners who are part of accountable care organizations, it is unclear where this amount of improvement provided by botulinum toxin fits among existing alternative treatment options. For chronic migraine, data exist that it is cost-effective, depending of course on an agreed-upon cost per quality-adjusted life-year. ${ }^{7}$ As successfully treated patients become headache-free, the practitioner will be faced with the decision of when to switch to a less costly preventive option.

In the setting of accountable care organizations and other future health care delivery models, physicians will increasingly become stewards of cost-effectiveness. Medical economic analyses will be needed to determine the most cost-effective means of improving patients' quality of life. Some value judgments will come into play, but there will be an increasing need to explore pertinent endpoints while understanding the reality of the variability of individual patient needs. Although spasticity (by various measures) is reduced with botulinum toxin therapy, functional endpoints are much less consistently met. Pretreatment discussion with the patient or caregiver to set reasonable and worthwhile goals should help determine whether or not to continue treatment after an initial trial.

Botulinum toxin therapy has proven to be a powerful tool in the treatment of a number of neurologic disorders. The development of 2 serotypes and several formulations has added to the options available to the practicing neurologist. With appropriate attention to the differences in formulation dosing and side effect profiles where they exist, along with appropriate patient selection, this therapy will continue to bring notable value-added improvement in patients' lives.

\section{REFERENCES}

1. Simpson DM, Hallett M, Ashman EJ, et al. Practice guideline update summary: botulinum neurotoxin for the treatment of blepharospasm, cervical dystonia, adult spasticity, and headache: report of the Guideline Development Subcommittee of the American Academy of Neurology. Neurology Epub 2016 Apr 18.

2. Govindarajan R, Shepard KM, Moschonas C, Chen JJ. Botulinum neurotoxin for the treatment of blepharospasm, cervical dystonia, adult spasticity, and headache: payment policy perspectives. Neurol Clin Pract 2016;6:281-286.

3. Roger Aoki K. Botulinum neurotoxin serotypes A and B preparations have different safety margins in pre-clinical models of muscle weakening efficacy and systemic safety. Toxicon 2002;40:923-928.

4. Chapman MA, Barron R, Tanis DC, Gill CE, Charles PD. Comparison of botulinum neurotoxin preparations for the treatment of cervical dystonia. Clin Ther 2007;29:1325-1337.

5. Brin MF, Fahn S, Moskowitz C, et al. Localized injections of botulinum toxin for the treatment of focal dystonia and hemifacial spasm. Movement Disord 1987;2:237-254.

6. Jost WH, Kohl A. Botulinum toxin: evidence-based medicine criteria in blepharospasm and hemifacial spasm. J Neurol 2001;248(suppl 1):21-24.

7. Batty AJ, Hansen RN, Bloudek LM, et al. The cost-effectiveness of onabotulinumtoxinA for the prophylaxis of headache in adults with chronic migraine in the UK. J Med Econ 2013;16:877-887. 


\section{AUTHOR CONTRIBUTIONS}

Drafting/revising the manuscript.

\section{STUDY FUNDING}

No targeted funding reported.

\section{DISCLOSURES}

R.L. Barbano served on a scientific advisory board for Allergan; serves as an associate editor for Neurology: Clinical Practice; performs botulinum toxin injections at the University of Rochester (30\% effort); receives research support from Allergan, Vaccinex, and Biotie; has received research support from NIH, NINDS, ORDR: Dystonia Coalition Projects, Site PI; holds stock/stock options in VisualDx; and has served as an expert witness in legal proceedings including malpractice, not involving commercial entities. Full disclosure form information provided by the author is available with the full text of this article at Neurology.org/cp.

\section{Discover Altmetrics}

See real-time downloads and online activity for articles!

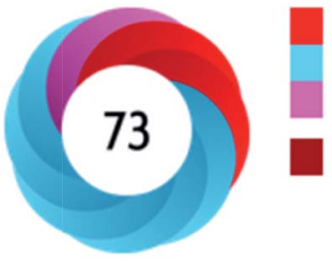

Picked up by 8 news outlets

Tweeted by 18

Mentioned in 1 Google+ posts

12 readers on Mendeley

See more details

Authors and readers alike can view real-time data on articles including downloads and online activity across multiple sources. Click on the "Article Metrics" link in the right column of an article for details. To learn more about article metrics visit http://www. neurology.org/site/includefiles/article_usage.xhtml. 


\title{
Neurology ${ }^{\circ}$ Clinical Practice
}

\author{
Botulinum toxins in clinical practice: Gaps in knowledge \\ Richard L. Barbano \\ Neurol Clin Pract 2016;6;206-208 Published Online before print April 18, 2016 \\ DOI 10.1212/CPJ.0000000000000244
}

This information is current as of April 18, 2016

\begin{abstract}
Updated Information \&
Services

including high resolution figures, can be found at:

http://cp.neurology.org/content/6/3/206.full.html

References

This article cites 6 articles, 1 of which you can access for free at: http://cp.neurology.org/content/6/3/206.full.html\#\#ref-list-1

Subspecialty Collections

This article, along with others on similar topics, appears in the

following collection(s):

Blepharospasm

http://cp.neurology.org//cgi/collection/blepharospasm

Botulinum toxin

http://cp.neurology.org//cgi/collection/botulinum_toxin

Dystonia

http://cp.neurology.org//cgi/collection/dystonia

Migraine

http://cp.neurology.org//cgi/collection/migraine

Permissions \& Licensing

Information about reproducing this article in parts (figures,tables) or in its entirety can be found online at:

http://cp.neurology.org/misc/about.xhtml\#permissions

Reprints

Information about ordering reprints can be found online:

http://cp.neurology.org/misc/addir.xhtml\#reprintsus
\end{abstract}

Neurol Clin Pract is an official journal of the American Academy of Neurology. Published continuously since 2011, it is now a bimonthly with 6 issues per year. Copyright ( 2016 American Academy of Neurology. All rights reserved. Print ISSN: 2163-0402. Online ISSN: 2163-0933.

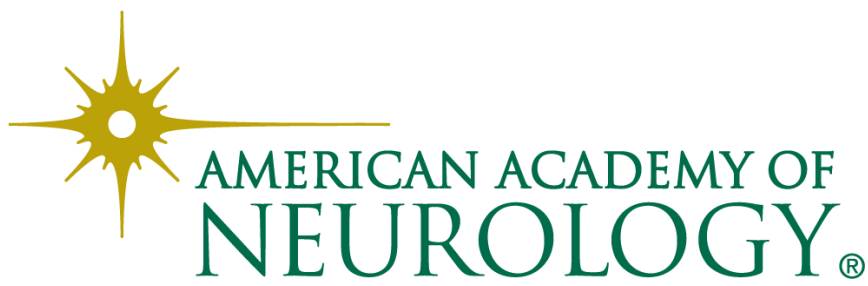

